\title{
PICTURE BOOKS AND HEALTHY EATING HABITS: AN INTERVENTION STUDY IN A GREEK PRESCHOOL SETTING
}

\author{
Eleni Tympai, \\ Vasiliki Karavida \\ Department of Early Years Learning \& Care, \\ University of Ioannina, \\ Greece
}

\begin{abstract}
:
Experiences with food preferences begin in infancy and continue to develop on children transition to solid food. Children's food preferences are influenced by availability and familiarity with foods as well as parental modeling and health related picture books. The aim of the study was to evaluate whether picture-books regarding healthy lifestyle can influence children's eating preferences. A questionnaire related to the use of picturebooks at home and lifestyle habits was distributed to all parents. Picture-books were provided to all parents. At the same time children were allocated in two groups: the intervention group, which took part in further activities (cooking), and to a comparison group. Interviews were addressed to the parents after the program. The ethical concern included confidentiality assurance and the choice to withdraw. Findings revealed that the daily reading of books about food was increased in both groups. Most of the families of the intervention group reduced fast food and sweet consumption and increased outdoor activities. Implications on the influence of books and additional activities on promoting child attitudes on healthy food will be discussed.
\end{abstract}

Keywords: early childhood, picture books, nutrition, healthy lifestyle, educational activities

\section{Introduction}

There are many factors that have an impact on children's nutrition habits, such as their family background and their school education. During the last years, children's eating habits have been studied a lot and there has been a big discussion over the manners that have to be used in order to change them when required (Scaglioni et al., 2018). These studies are essential due to the increase that has been observed in the childhood obesity rates, which is linked to children's experiences related to food and their family background. Moreover, the eating habits are formed in the early years of an individual,

i Correspondence: email etimpa@uoi.gr 
thus, it is crucial to understand how they are formed through the experiences during childhood, since adopting a healthy lifestyle for children requires positive experiences from an early age (Smethers, and Rolls, 2018).

\section{Literature Review}

There is a high correlation between a person's health and the adopted eating habits. Health as a term does necessarily mean the absence of a disease but is also linked to a person's mental and physical well-being. Thus, health is a basic determinant of an individual's quality of life, along with the level of independence, the psychological state and the relationships with other individuals (Saxen, and Orley, 1997). As far as the domain of nutrition is concerned, it consists a major factor that has a direct impact on a person's health. Healthy nutrition helps for the prevention of diseases, as well as for the enhancement to a person's physical condition, since the occurrence of diseases is related to three major factors: environment, behavior and genetics (Trovato, 2012). A child's interests change throughout the years and, children are majorly influenced by adults such as their care providers and teachers. At this stage, the child chooses to eat when the feeling of hunger exists and does not use food in order to attract attention (de Villiers et al., 2016).

As mentioned above, during the first years of a child's life, many changes take place and the cognitive ability as well as the language skills show a tremendous increase due to the brain's increased plasticity at this period, which gradually deteriorates (Tierney, and Nelson, 2013). Simultaneously, toddlers and infants also evolve in the domain of eating, since they experience a transition from milk nutrition to the solid food (Mura Paroche et al., 2017). According to WHO, complementary feeding should occur at 6 months, whereas other researchers propose to begin weaning in 4 months (WHO, 2005). At this age, the children's caregivers are responsible for the children's nutrition and an autonomous eating attitude is only formed after three or four years since young children imitate their culture's adult diet (Savage et al., 2007). Thus, the eating behaviors rely on the first years and this early period might have a positive or a negative impact in the eating habits what are sometimes related to fighting non-communicable diseases (Faith, and Kral, 2006; Birch et al., 2007).

There have been several studies into the determinants of human eating attitudes and they have examined many elements that play a vital role, without understanding clearly though the real contribution of each element (Blodgett Salafia et al., 2015; Bowman et al., 2004). However, the knowledge of the mechanisms that are related to food habits could be helpful to healthcare professionals who might assist for the adaptation of healthy food practices for children. Therefore, studying the children's behavior should be considered as a starting point for new nutrition education programs, and simultaneously further research strategies should be suggested in order to interpret more effectively the interactions between random factors affecting children's eating behaviors and their attitudes (Sobko et al., 2017; Khan, and Bell, 2019). 
According to experts' guidelines across the EU, children should receive adequate portions from all nutrition groups which have to be distributed evenly across the day, depending on the requirements for their age (Inchley, 2016). Children's dietary choices and habits derive from the interaction the individual's microenvironment and macroenvironment, whilst other studies suggest that humans are born with specific preferences regarding food (Shankar, 2017). It has been observed that infants' reactions differ while tasting sweet, bitter or sour liquids, which indicates that genes play in fact a crucial role (Nekitsing et al., 2018).

In addition to biologically predetermined taste preferences, another equally important factor is the experiences that children acquire while observing their parents during infancy (Faith, and Kral, 2006). Moreover, the family plays a crucial role in determining a child's eating habits due to the child's tendency to imitate the older members of the family. As far as the school environment is concerned, the greatest influence is exerted by teachers, who act as role models, promoting or discouraging a particular health behavior (Kupolati et al., 2018).

Intervention programs at school, even those which take place as early as the preschool age, contribute to healthy habits concerning food (Karavida et al., 2020). The efficacy of such sensory interaction programs considers the components of these that are likely to encourage food acceptance. Repeated exposure to a food's flavor has robust empirical support in terms of its potential to increase food intake. These programs, in addition to the collaboration of the triangle school-children-parents, help to create alternative uses of food and to adopt healthy eating preferences (Dazeley et al., 2012; Tympa et al., 2019).

There has been a great debate over the impact of books reading to the children's nutrition habits (Birch, 2007). In the current study, the effect of picture books on the children's behavior is going to be discussed. A picture book contains visual imprints that are related to each other and to the verbal text as well. Many researchers point out that in a picture book the story depends on the interaction between text and image, as both of them have been created for a very specific aesthetic purpose (van den Heuvel-Panhuizen et al., 2016). Picture books seem to share two different ways of communicating - words and images, which implies the existence of two languages in the picture books, the language as a series of words and the language as a series of images. In picture books, images and text do not simply coexist, but interact in a variety of ways, producing different meanings each time. Thus, the illustrator is a parallel writer since the image has its own life and function, making essential for picture books a more holistic approach for reading them (England et al., 2015).

One basic benefit of reading picture books is that help to strengthen the relationship between adults and children and also, they give an interesting reading experience for every age (Hui et al., 2019). Many researches have shown that toddlers are able to use the symbolic relationship that exists between objects and pictures in order to interpret the real world (England et al., 2015). Furthermore, imitating attitudes has been observed while using picture books. In some studies, the time required for children to 
look at target foods was affected by the familiarity that they had with them through the pictures they were exposed to (Scaglioni et al., 2018).

The main aim of the current study was to evaluate whether picture books regarding healthy lifestyle can influence children's eating preferences and willingness for physical activities. The secondary aim was to test the hypothesis that the intervention activities at school may induce positive changes in physical activity levels, eating preferences and activity habits in preschool children.

\section{Material and Methods}

A quasi-experimental intervention study was conducted. Quasi-experimental studies include a broad range of nonrandomized intervention studies and are frequently used when it is not logistically feasible or ethical to conduct a randomized controlled trial (Harris et al., 2006). The current study took place in a Greek preschool setting and the intervention and comparison group, consisted by the two neighbor classes with 25 children each classroom at the same age and the same sex distribution.

In this study a questionnaire and semi-structured interviews took place with all parents from both the intervention and the comparison group, in order to examine their opinion about the impact of picture books reading with healthy food at school and at home as well. All the parents were reading stories at home from the picture books they were provided from the school, but further picture books reading took place only in the intervention group at school, whereas the comparison group followed a different curriculum in the classroom. The children from the two groups were at the same age (45 years old), did not have significant differences regarding their eating habits, their health condition, their family income and their parent's background according to the registration files in the preschool setting, hence the study was not biased and the separation in two groups was done properly.

\subsection{Participants}

The sample consisted of 50 children aged between 4 and 5 years old, that were all reported to have normal vision and hearing. Fifty parents of the two classrooms participated in the study. Demographic information showed that $97 \%$ of the participating families were of Greek ethnicity and $76 \%$ of the sample included at least one carer who was highly educated.

\subsection{Materials}

Picture books and a questionnaire was used for both the intervention and the comparison group. Picture books with topics like non-familiar foods, nutritional habits, heart's function and body issues, were provided to all parents from the preschool setting's library. Parents could refresh the books as often as their children wanted. The researchers made sure to have more copies of each book so that there would be no protests. The questionnaire included open questions that were answered by all parents in both groups 
and the questions were related to their demographic and socio-economic background, their children's attitude towards healthy foods and unhealthy snacks, as well as their physical activity habits.

\subsection{Procedure}

The first contact with the parents took place during a formal meeting of school parents at the beginning of the school year, where the experiment was described briefly. After being given the consent, the children were split into two groups, the intervention group $(n=25)$ and the comparison group ( $n=25)$, according to the classroom's initial distribution. It was randomly selected which class would belong to the intervention group and which to the comparison group. Parents were given picture books that involved healthy foods and they were asked to read these books to their children daily for two weeks. The intervention group at school was reading extra picture books regarding to healthy eating and following an educational program with cooking, tasting, feeling, fine arts and motor activities every day for two weeks, whereas the comparison group followed a different educational curriculum. Two weeks after the interventions with the picture books, an appointment was arranged with all the parents and semi structure interviews took place.

\subsection{Ethical issues}

The ethical concern included written concern by the parents, confidentiality assurance and the choice to withdraw at any time. Regarding the interviews, the parents were informed that the results would be used exclusively for research purposes and there would be respect for the data.

\subsection{Data analysis}

In the current analysis, quantitative and qualitative approaches had been adopted and the analysis was done with IBM SPSS 26.0 software.

\section{Results}

In order to test whether the data was appropriate for parametric analyses, we used the Q-Q plots that confirmed that the observations approximately followed the normal distribution. Twenty-five children were included in the comparison group and 25 children in the intervention group and the questionnaires were answered by 50 parents. No correlation was found between the number of interventions and the total time spent in books, $\mathrm{r}(118)=-0.01, \mathrm{P}=0.70$, and no exclusions of outliers was made. The difference between the comparison group and the intervention group regarding the demand for vegetables after the interventions was significant, $\chi 2=4.00, \mathrm{P}<0.05$, as well as the demand for sweets, $\chi 2=4.05, \mathrm{P}<0.05$.

In general, the pretest revealed that most of the parents didn't use to read books about nutrition whereas $70 \%$ started nutrition books reading after the program. The children from the intervention group showed more eagerness to adopt a healthier 
lifestyle than the children who followed the different curriculum. A chi squared test was conducted in order to check whether mother's education level, the family income, and father's education level play a significant role to nutrition reading before and after the experiment. Based on the results, it was found that mother's education level plays a significant role, $\chi 2=4.33, \mathrm{P}<0.05$, whereas father's education level was not found to have a severe impact on the children's attitude towards nutrition reading. As far as the nutrition habits are concerned, chi squared test showed that the intervention group changed their attitude towards healthy foods, and this can also be observed through the following charts (Figure $1 \& 2$ ).

Figure 1: Vegetables consumption prior to picture book reading based on the family income

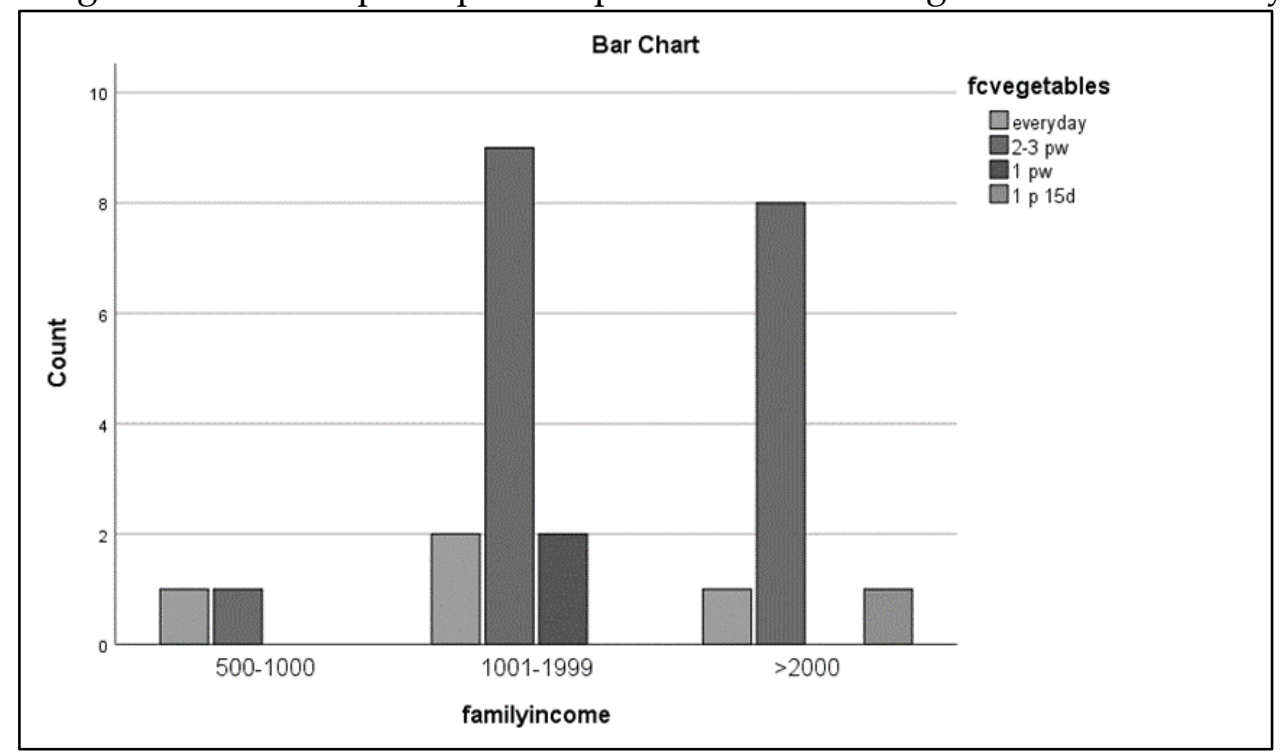

Figure 2: Vegetables consumption after picture book reading based on the family income

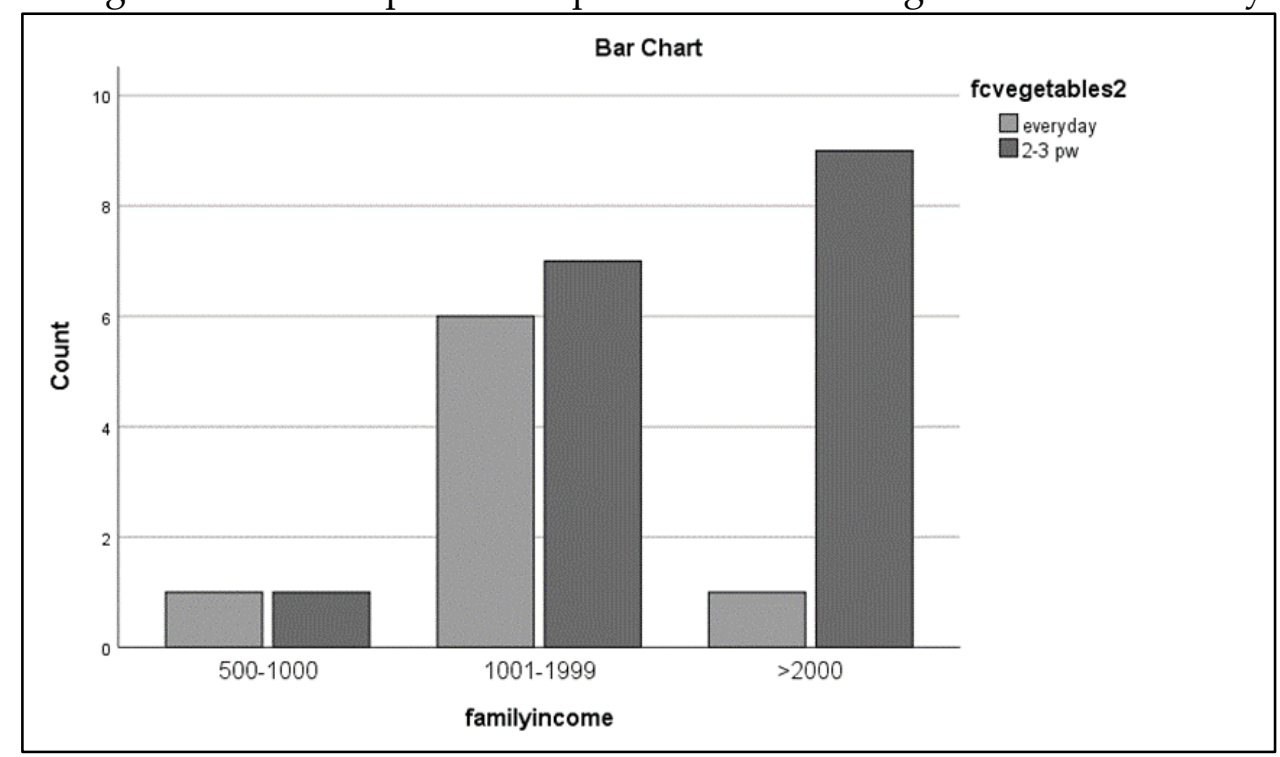

The results from Figures $1 \& 2$ indicate that the family's income played a crucial role to the increase of vegetables consumption. It appears that the eating habits of the 
children whose family has a low income has not altered, a result that is consistent with the findings of French et al, who demonstrated that households with a lower income purchase food that is less healthy compared with households with a higher income (French et al., 2019). Thus, accepting the concept of reciprocal determinism, children's parents influence their children's behaviors through the alterations to their social or physical environment (Zhen-Duan et al., 2019).

Figure 3: Consumption of sweets based on the level of education of the mother prior to picture book reading

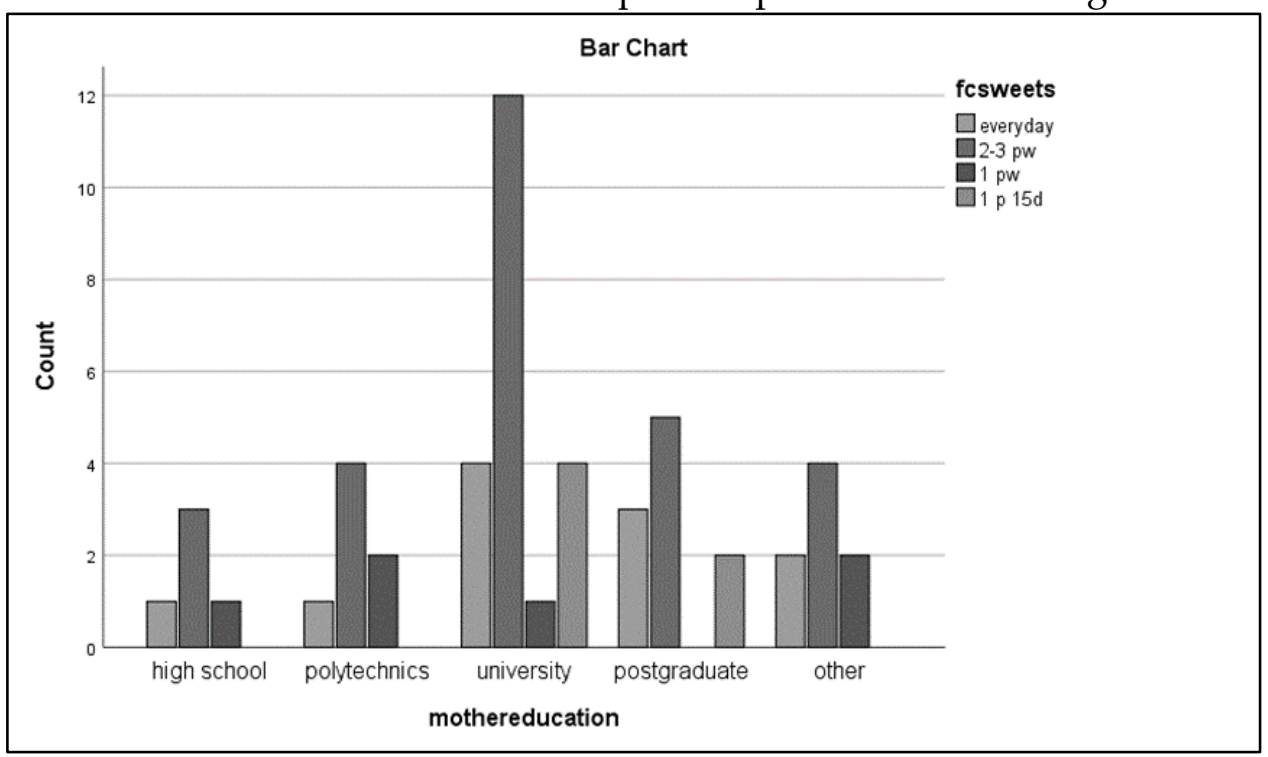

Figure 4: Sweet consumption post picture book reading related to the educational level of the mother

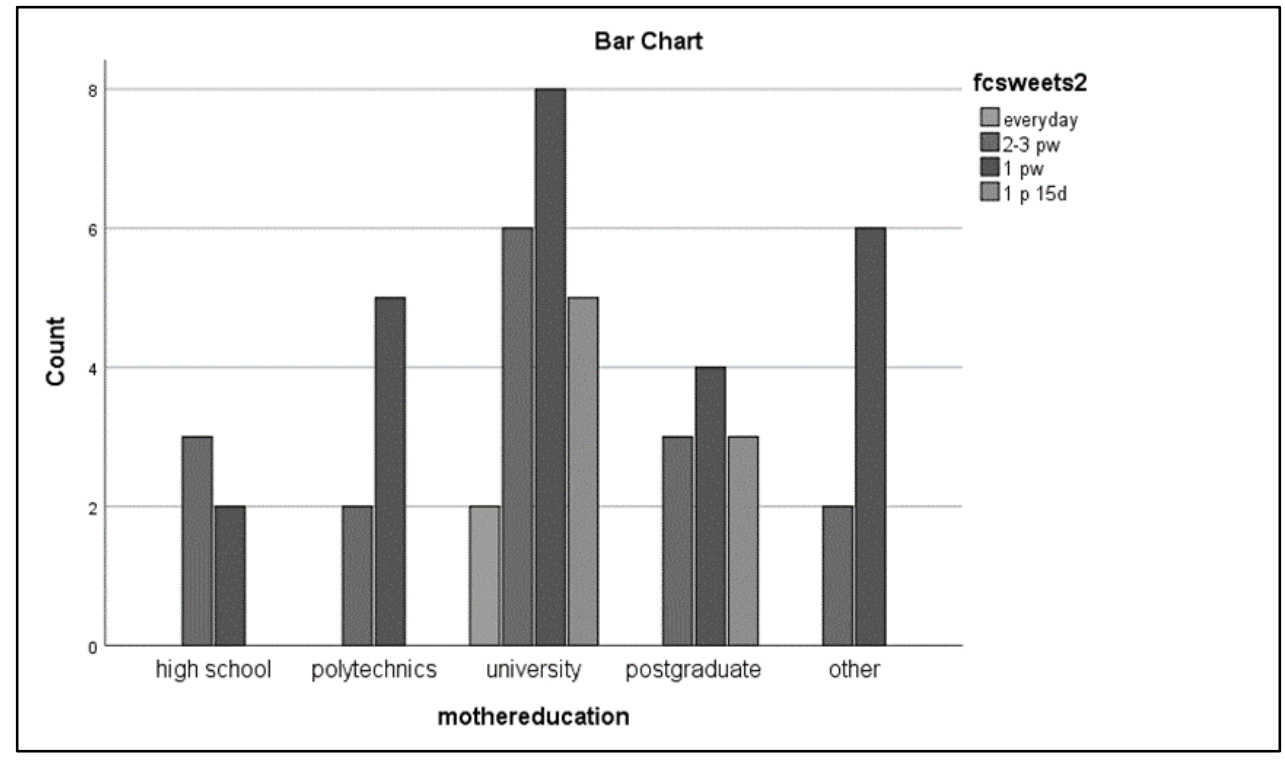

Figures 3 and 4 demonstrate the impact of the mother's education level mentioned above. It appears that mothers who are highly educated try to give more stimuli to their children for the adoption of a healthier lifestyle, which is an outcome that is aligned to 
the conclusions in previous studies that indicated that maternal education level affect children's eating behavior, as well as the socio-economic disparities (van Ansem et al., 2014).

Figure 5: Change to the means of transport used

by the comparison and the intervention group.

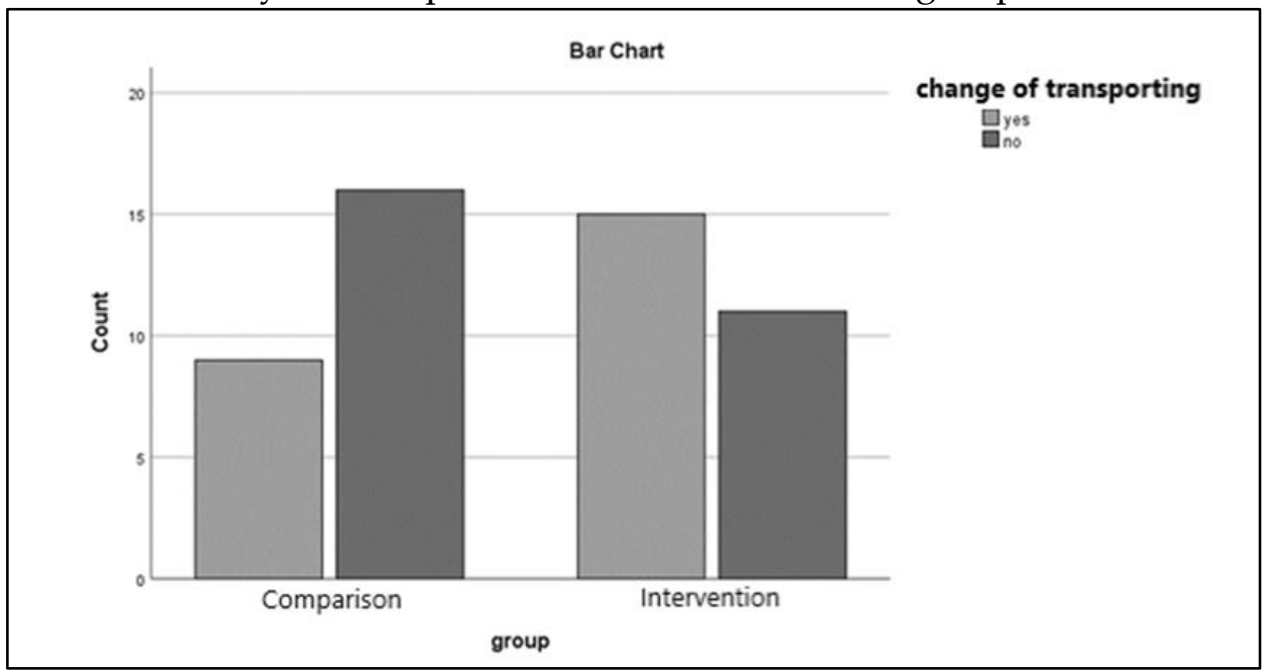

The intervention group showed more eagerness to change the way of transportation from home to school -walking instead of driving them to school- a result that is illustrated in figure 5 and is also consistent to the information provided in the parents' interviews and the results of previous studies that illustrated a significant effect deriving from reading storybooks for the encouragement of the adoption of a healthy lifestyle amongst children (Pulimeno et al., 2020).

A sample of parents' quotes from the intervention group follow:

"I noticed that my son asks more and more to read books to him at home." (Parent 1)

"Both of them remark us when we offer an unhealthy snack." (Parent 2)

"We are impressed by their knowledge regarding cooking, food ingredients and healthy habits when they return from school." (Parent 3)

"She forces me to come to school on foot, which delays me in my work." (Parent 4)

A sample of parents' quotes from the comparison group follow:

"Our child introduced reading at home and that was enjoyable." (Parent 1)

"Talking to the other parents we noticed that our child did not mention any cooking activities or anything else happened at school." (Parent 2) 
"In any case reading healthy books at home pushed us to think more about healthy habits and made us wonder how much we follow them." (Parent 3)

"I was impressed that he tries new taste like aubergine." (Parent 4)

\section{Discussion}

This quasi-experimental study comes to add some conclusions regarding children's attitude towards healthy nutrition. According to the results from the research that was conducted, picture-books appear to play a positive role on the children's behavior towards healthy food. Subjects from the intervention group, changed their food preferences since they asked for more vegetables and healthy food, and their demand for sweets showed a dramatic decrease. Moreover, the children that were included in the intervention group showed changed the means of transport that were using and generally changed their attitude towards a healthier lifestyle.

Previous studies have shown that prior exposure of children visually to pictures of food have an impact to their taste and to the neophobia. The study conducted by Houston- Price et al, demonstrated a more positive attitude to the food they were familiar with, whereas, the amount of neophobia was reduced (Houston-Price et al., 2009). Moreover, this research delved more into the children's perception of food, since the results show that the exposure to food exerts a basic impact on children's eagerness to taste new healthy foods, based on whether the food was familiar or not familiar to them. Other studies indicate that the use of picture books ameliorates the level of familiarization of children to random foods, as well as their eagerness to taste vegetables. Deterioration of the levels of neophobia in the vegetable book group was observed in the research conducted by Owen et al, demonstrating a positive attitude for tasting new types of food for children who read the vegetable book (Owen et al., 2018).

The review conducted by Nekitsing et al., revealed a significance to the interventions that promote vegetable intake by preschool children, but future research was suggested in order to examine whether integrating taste exposure as well as sensory learning strategies along with nutrition education should be added in the preschool curriculum (Nekitsing et al., 2018). In our research, picture book reading was done by all caregivers in both the intervention and the comparison group. However, food and cooking activities took place in the class of the intervention group, thus, the role of the education specialists is crucial. The same results derive from according to participants, both children and teachers developed a sensory language; children became more positive towards tasting and teachers discovered new possibilities for interdisciplinary work. However, the results also show that an allowing system, with both an interested and confident teacher who recognizes the competent child and a supportive organization, is needed in order to make food a meaningful tool for learning in preschool. The results show that nutritional education is crucial for the adaptation of healthy food habits by preschoolers, conclusion that derives from the positive impact of the picture books for 
the intervention group. Including food education within the preschool curriculum in order to assist the preschoolers to adopt a healthy lifestyle from their early years is also suggested by Höijer (Sepp, and Höijer, 2016).

Based on the interviews with the children's parents after the interventions, most of them seemed very pleased with the outcomes of the experiment.

\section{"My son hasn't asked for any sweets after reading the picture book!" (Parent 1)}

This was stated by a child's mother who was a member of the intervention group. Even though the results were more significant in this specific group due to the interventions that simultaneously took place at school, the parents of the comparison group were satisfied as well since they observed a positive effect on the family bonds through picture book reading.

"My daughter enjoys spending more time with me and reading fairy tales at night became a permanent habit!" (Parent 2)

From a pedagogic aspect, stories through picture books convey basic principles that are crucial for infants' lives. From a didactic perspective, storybooks consist of a precious resource for preschool, enhancing children's' skills and depriving them from unhealthy addictions and habits (Pulimeno et al., 2020).

Active transportation for going to school is a crucial contributor to the physical activity of children and adolescents and successful strategies for its adaptation has been suggested in the past that have to be tested (Chillon et al., 2011). In our research, an increase to the active transportation was observed, which is a conclusion that is also stated from a parent:

"My son demands to go to school on foot instead of driving him there before I go to work". (Parent 3)

When preschool children are exposed to pictures of specific vegetables, the probability that their intake of the targeted vegetables is increased (Rioux et al., 2018). This assumption is strengthened by our research and it is clearly stated by a child's mother in the experimental group:

"My child wants to try more "difficult" foods at home and random vegetables". (Parent 1)

\section{Conclusion}

In conclusion, this research confirms the benefits of reading picture books at school and home in order to familiarize infants to healthy food and promote its intake amongst them. 
This age is crucial for them due to the establishment of lifelong patterns that takes place; thus, the promotion of healthy foods has to be strengthened by various means. Lifelong eating patterns are established at an early age, and the link between fruit and vegetable consumption in early childhood and healthy eating in later life is well-documented (Maynard et al., 2003). There were some limitations of the study that are related to the lack of follow-up after a longer period and the fact that all the subjects of the sample were not children from different preschool settings. Thus, further research is required if we want to examine the long-term effects of reading picture books in both school for the promotion of healthy nutrition.

\section{Disclosure Statement}

No potential conflict of interest was reported by the authors.

\section{About the Author(s)}

Dr. Eleni Tympa is an Assistant Professor at the Department of Early Years Learning and Care at the University of Ioannina, Greece. Her research focus is on the healthy life style of preschool children, the role of the story telling on the healthy life style, the pretend play and art activities and their contribution to the child's development.

Dr. Vasiliki Karavida is an Assistant Professor at the department of Early Years Learning \& Care at the University of Ioannina, Greece. Her areas of research involve nutrition, education and all-round development in early childhood.

\section{References}

Birch L, Savage JS, Ventura A, 2007. Influences on the Development of Children's Eating Behaviours: From Infancy to Adolescence. Canadian Journal of Dietetic Practice and Research 68(1): s1-s56.

Blodgett SEH, Jones ME, Haugen EC, Schaefer MK, 2015. Perceptions of the causes of eating disorders: a comparison of individuals with and without eating disorders. Journal of Eating Disorders 3: 32. https://doi.org/10.1186/s40337-015-0069-8

Bowman SA, Gortmaker SL, Ebbeling CB, Pereira MA, Ludwig DS, 2004. Effects of fastfood consumption on energy intake and diet quality among children in a national household survey. Pediatrics $113(1 \quad$ Pt $\quad 1): \quad 112-118$. https://doi.org/10.1542/peds.113.1.112

van Ansem WJC, Schrijvers CT, Rodenburg G, van de Mheen D, 2014. Maternal educational level and children's healthy eating behaviour: role of the home food environment (cross-sectional results from the INPACT study). International Journal of Behavioral Nutrition and Physical Activity 11: 113. https://doi.org/10.1186/s12966-014-0113-0 
Chillón P, Evenson KR, Vaughn A, Ward DS, 2011. A systematic review of interventions for promoting active transportation to school. International Journal of Behavioral Nutrition and Physical Activity 8: 10. https://doi.org/10.1186/1479-5868-8-10

Dazeley P, Houston-Price C, Hill C, 2012. Should healthy eating programmes incorporate interaction with foods in different sensory modalities? A review of the evidence. $\begin{array}{lllll}\text { British Journal of Nutrition } 108 \quad \text { (514): } & \text { 769-777. }\end{array}$ https://doi.org/10.1017/S0007114511007343

England JL, Linchey J, Madsen KA, Patel AI, 2015. Reach Out and Eat: Food and Beverages Depicted in Books for Preschoolers. Clinical Pediatrics 54(13): 12571264. https://doi.org/10.1177/0009922815574078

Faith MS, Kral TVE, 2006. Social Environmental and Genetic Influences on Obesity and Obesity-Promoting Behaviors: Fostering Research Integration. In: Institute of Medicine (US) Committee on Assessing Interactions Among Social, Behavioral, and Genetic Factors in Health; Hernandez LM, Blazer DG (Eds.), Genes, Behavior, and the Social Environment: Moving Beyond the Nature/Nurture Debate. Washington (DC): National Academies Press (US). Available from: https://www.ncbi.nlm.nih.gov/books/NBK19935/

French SA, Tangney CC, Crane MM, Wang Y, Appelhans BM, 2019. Nutrition quality of food purchases varies by household income: the SHoPPER study. BMC Public Health 19(1): 231. https://doi.org/10.1186/s12889-019-6546-2

van den Heuvel-Panhuizen M, Elia I, Robitzsch A, 2016. Effects of reading picture books on kindergartners' mathematics performance. Educational Psychology 36(2): 323346. https://doi.org/10.1080/01443410.2014.963029

Harris AD, McGregor JC, Perencevich EN, Furuno JP, Zhu J, Peterson DE, Finkelstein J, 2006. The Use and Interpretation of Quasi-Experimental Studies in Medical Informatics. Journal of the American Medical Informatics Association 13(1): 16-23. doi: 10.1197/jamia.M1749

Hui A, Chow BW, Chan E, Leung MT, 2020. Reading Picture Books with Elements of Positive Psychology for Enhancing the Learning of English as a Second Language in Young Children. Frontiers in Psychology 10: 2899. https://doi.org/10.3389/fpsyg.2019.02899

Inchley J, Currie D, Young T, Samdal O, Torsheim T, Augustson L, et al. 2016. Growing up unequal: gender and socioeconomic differences in young people's health and well-being. Health Behaviour in School-aged Children (HBSC) study: international report from the 2013/2014 survey. Copenhagen: WHO Regional Office for Europe.

Karavida V, Tympa E, Panousis G, 2020. Parent-child collaboration preventing obesity and acquiring a healthy lifestyle: A review study. International Journal of Humanities and Social Science 10(12): 151-155. doi:10.30845/ijhss.v10n12p20

Khan M, Bell R, 2019. Effects of a School Based Intervention on Children's Physical Activity and Healthy Eating: A Mixed-Methods Study. International Journal of 
$\begin{array}{llllll}\text { Environmental Research and Public Health 16(22): } 4320 . & \text {. }\end{array}$ https://doi.org/10.3390/ijerph16224320

Kupolati M D, MacIntyre UE, Gericke GJ, 2018. A Theory-Based Contextual Nutrition Education Manual Enhanced Nutrition Teaching Skill. Frontiers in Public Health 6: 157. https://doi.org/10.3389/fpubh.2018.00157

Maynard M, Gunnell D, Emmett P, Frankel S, Davey Smith G, 2003. Fruit, vegetables, and antioxidants in childhood and risk of adult cancer: The Boyd Orr cohort. Journal of Epidemiology \& Community Health 57(3): 218-25. doi: 10.1136/jech.57.3.218

Mura Paroche M, Caton SJ, Vereijken C, Weenen H, Houston-Price C, 2017. How Infants and Young Children Learn About Food: A Systematic Review. Frontiers in Psychology 8: 1046. https://doi.org/10.3389/fpsyg.2017.01046

Nekitsing C, Hetherington MM, Blundell-Birtill P, 2018. Developing Healthy Food Preferences in Preschool Children Through Taste Exposure, Sensory Learning, and Nutrition Education. Current Obesity Reports 7(1): 60-67. https://doi.org/10.1007/s13679-018-0297-8

Pulimeno M, Piscitelli P, Colazzo S, 2020. Children's literature to promote students' global development and wellbeing. Health Promotion Perspectives 10(1): 13-23. https://doi.org/10.15171/hpp.2020.05

Rioux C, Lafraire J, Picard D, 2018. Visual exposure and categorization performance positively influence 3- to 6-year-old children's willingness to taste unfamiliar vegetables; Appetite 120: 32-42. doi: 10.1016/j.appet.2017.08.016

Saxena S, Orley J, 1997. Quality of life assessment: The world health organization perspective. European Psychiatry, 12 (Suppl 3), 263s-6s. doi: 10.1016/S09249338(97)89095-5

Savage JS, Fisher JO, Birch LL, 2007. Parental influence on eating behavior: conception to adolescence. The Journal of law, medicine \& ethics: a journal of the American Society of Law, Medicine \& Ethics 35(1): 22-34. https://doi.org/10.1111/j.1748720X.2007.00111.x

Scaglioni S, De Cosmi V, Ciappolino V, Parazzini F, Brambilla P, Agostoni C, 2018. Factors Influencing Children's Eating Behaviours. Nutrients 10(6): 706. https://doi.org/10.3390/nu10060706

Shankar K, Pivik RT, Johnson SL, van Ommen B, Demme, E, Murray R, 2017. Environmental Forces that Shape Early Development: What We Know and Still Need to Know. Current Developments in Nutrition 2(8): nzx002. https://doi.org/10.3945/cdn.117.001826

Smethers AD, Rolls BJ, 2018. Dietary Management of Obesity: Cornerstones of Healthy Eating Patterns. The Medical Clinics of North America 102(1): 107-124. https://doi.org/10.1016/j.mcna.2017.08.009

Sobko T, Jia Z, Kaplan M, Lee A, Tseng C, 2017. Promoting healthy eating and active playtime by connecting to nature families with preschool children: evaluation of pilot study "Play \& Grow". Pediatric Research 81: 572-581 
Tierney AL, Nelson CA, 3rd. 2009. Brain Development and the Role of Experience in the Early Years. Zero to Three 30(2, 9-13.

Trovato GM, 2012. Behavior, nutrition and lifestyle in a comprehensive health and disease paradigm: skills and knowledge for a predictive, preventive and personalized medicine. The EPMA Journal 3(1): 8. https://doi.org/10.1007/s13167$\underline{012-0141-2}$

Tympa E, Karavida V, Pashali T, Psyrropoulos Z, 2019. The “Cr-EAT-Ive Schools Feasibility Study": Aiming to Reduce Food Waste by Implementing Relevant Actions including the Completion of Food Waste Diaries by Kindergarten Families. Journal of Education \& Social Policy 6(4): 80-85. doi:10.30845/jesp.v6n4p11

de Villiers A, Steyn NP, Draper CE, Hill J, Gwebushe N, Lambert EV, Lombard C, 2016. Primary School Children's Nutrition Knowledge, Self-Efficacy, and Behavior, after a Three-Year Healthy Lifestyle Intervention (HealthKick). Ethnicity \& Disease 26(2): 171-180. https://doi.org/10.18865/ed.26.2.171

WHO, 2005. Guiding principles for feeding non-breastfed children 6-24 months of age. Geneva: World Health Organization.

Zhen-Duan J, Engebretsen B, Laroche HH, 2019. Diet and physical activity changes among low-income families: perspectives of mothers and their children. International Journal of Qualitative Studies on Health and Well-being 14(1): 1658700. https://doi.org/10.1080/17482631.2019.1658700. 
Creative Commons licensing terms

Author(s) will retain the copyright of their published articles agreeing that a Creative Commons Attribution 4.0 International License (CC BY 4.0) terms will be applied to their work. Under the terms of this license, no permission is required from the author(s) or publisher for members of the community to copy, distribute, transmit or adapt the article content, providing a proper, prominent and unambiguous attribution to the authors in a manner that makes clear that the materials are being reused under permission of a Creative Commons License. Views, opinions and conclusions expressed in this research article are views, opinions and conclusions of the author(s). Open Access Publishing Group and European Journal of Education Studies shall not be responsible or answerable for any loss, damage or liability caused in relation to/arising out of conflicts of interest, copyright violations and inappropriate or inaccurate use of any kind content related or integrated into the research work. All the published works are meeting the Open Access Publishing requirements and can be freely accessed, shared, modified, distributed and used in educational, commercial and non-commercial purposes under a Creative Commons Attribution 4.0 International License (CC BY 4.0). 